\title{
CLINICAL PROFILE OF ACUTE RESPIRATORY DISTRESS SYNDROME (ARDS) IN A TERTIARY CARE CENTRE/ HOSPITAL
}

\author{
Hemant R. Gupta ${ }^{1}$, Akhilesh Patidar², Utina Kichu³, Anish Kamble 4
}

${ }_{1}^{1}$ Associate Professor and Unit Head, Department of Medicine, Grant Government Medical College, Mumbai, Maharashtra, India. ${ }^{2}$ Senior Resident, Department of Medicine, JJ Group of Hospital and Grant Government Medical College, Mumbai, Maharashtra, India. 3Junior Resident, Department of Medicine, JJ Group of Hospital and Grant Government Medical College, Mumbai, Maharashtra, India. ${ }^{4}$ Senior Resident, Department of Medicine, JJ Group of Hospital and Grant Government Medical College, Mumbai, Maharashtra, India. ABSTRACT

\section{BACKGROUND}

ARDS is considered as the most severe form of acute lung injury, a form of diffuse alveolar injury and a leading cause of death in critical care settings.

Aims and Objectives-

- $\quad$ To analyse the ARDS cases in admitted patients with special reference to risk factors associated with poor prognosis.

- To study the aetiology of ARDS.

- $\quad$ To study severity and outcome of ARDS cases.

\section{MATERIALS AND METHODS}

This study was an observational study. It included 80 patients of ARDS, which are fulfilling diagnostic criteria according to Berlin definitions 2012. The study period was 1 year.

\section{RESULTS}

In critically ill patients who were hospitalised in Critical Care Units (CCU), the prevalence of ARDS has been estimated at about 5 $15 \%$ of patients. In our study period, there were 800 admissions with prevalence of ARDS of $12.50 \%$. Our results are consistent with those of Roupie et al, who reported a twice higher mortality (60\%) in patients with ARDS than that recorded in patients with mild ALI (31\%). Pulmonary infection (37.5\%) followed by Dengue (23.75\%) were the most common causes for ARDS in this study. In our study, sepsis was the predominant indirect cause of ARDS with 35 out of 80 patients of Dengue, i.e. 19 (23.75\%). There was a significant association between severity of ARDS and various aetiological groups with p-value of 0.0001 . Patients with ARDS had lower P02, lower P02/FiO2 ratio, severe metabolic acidosis, higher serum creatinine, higher blood urea nitrogen and worsened critical scores including GCS scoring, lower systolic blood pressure and lower mean arterial pressure.

\section{CONCLUSION}

1. Prevalence of acute respiratory distress syndrome is quite common in ICU setting.

2. Pulmonary infection was the most common non-tropical direct cause of ARDS, while sepsis was the most common cause of indirect ARDS.

3. Dengue, Malaria and Leptospirosis were most common tropical causes of ARDS.

4. Factors that showed association with mortality-

- Aetiology had significant association with outcome.

- Anaemia, tachycardia, raised ESR and high WBC count had significant association with outcome.

- Deranged serum creatinine and decreased urine output had significant association with outcome.

- Low systolic blood pressure and low diastolic blood pressure was significantly associated with poor outcome.

- Duration of ventilator support was associated with mortality significantly.

- Culture positivity was associated significantly with mortality.

\section{KEY WORDS}

ARDS.

HOW TO CITE THIS ARTICLE: Gupta HR, Patidar A, Kichu U, et al. Clinical profile of acute respiratory distress syndrome (ARDS) in a tertiary care centre/ hospital. J. Evolution Med. Dent. Sci. 2018;7(29):3279-3284, DOI: 10.14260/jemds/2018/739

'Financial or Other Competing Interest': None.

Submission 04-04-2018, Peer Review 28-06-2018,

Acceptance 04-07-2018, Published 16-07-2018.

Corresponding Author:

Dr. Hemant R. Gupta,

\#203, Erica Dosti Acres Complex,

Near Antop Hill Bus Depot,

Wadala (E), Antop Hill, Mumbai-400037,

Maharashtra, India.

E-mail: drhemantgupta@hotmail.com

DOI: $10.14260 /$ jemds $/ 2018 / 739$

\section{BACKGROUND}

Acute Respiratory Distress Syndrome (ARDS) was first described in 1967 in twelve patients presenting with acute respiratory failure that was refractory to oxygen therapy with decreased pulmonary compliance and diffuse infiltrates on chest x-rays. ${ }^{1}$ Although, this syndrome was given a name (at that time, "adult respiratory distress syndrome"), there was no well-established criteria for its diagnosis.

In 1988, a lung injury score was created in order to diagnose and evaluate ARDS severity, taking into account four parameters: chest x-ray, hypoxia through the oxygen 
tension/ fraction of inspired oxygen ratio, pulmonary compliance and positive end-expiratory pressure (PEEP). ${ }^{2}$

It was not until 1994 that the American European Consensus Conference on ARDS established diagnostic criteria for ARDS, defining it as a "syndrome of inflammation and increased pulmonary capillary permeability accompanied by a large number of clinical, radiological and physiological abnormalities, which are not caused by pulmonary capillary hypertension but may coexist with it."3 On that occasion, Acute Lung Injury (ALI) was defined as a clinical profile of acute respiratory failure with bilateral infiltrates on chest $\mathrm{x}$-ray. No left atrial hypertension (pulmonary capillary wedge pressure less than $18 \mathrm{mmHg}$ ) and hypoxaemia presenting an arterial oxygen tension/fraction of inspired oxygen ratio less than or equal to 300 . If this ratio is less than or equal to 200 , the patient is considered ARDS.

Since the 1994 American-European Consensus Conference on ARDS, at which the diagnostic criteria were redefined, the number of epidemiological studies has been steadily growing. In Intensive Care Units (ICUs), ARDS is seen in $2 \%$ to $26 \%$ of all hospitalised patients and the highest rates are observed among patients on mechanical ventilation. ${ }^{4-8,9}$ In a recent analysis of the ARDS Network Database, Goss et al estimated the incidence of ARDS in the US at 64 per $100,000.10$ In critically ill patients hospitalised in Intensive Care Units (ICUs), the prevalence of ALI/ARDS has been estimated at about 5 - $15 \%$ of patients. $(11,9,12,13)$

The principal risk factors for development of lung injury that have been identified since the first studies on ARDS carried out were sepsis, pneumonia, aspiration of gastric content, multiple trauma and shock due to multiple transfusions. ${ }^{14-17}$ This finding has been confirmed in more recent studies.6,7,8,18 In a study of 217 ARDS cases in Argentina, ${ }^{19}$ sepsis, pneumonia, shock and trauma were found to be the most frequent risk factors.

The Seattle study included three markers of severe trauma including multiple transfusions for emergency resuscitation ( $15 \mathrm{U}$ within a $24-\mathrm{h}$ period), multiple bone fractures or an unstable pelvic fracture and lung contusion. Of these, the category of multiple transfusions was associated with the highest incidence of ARDS 35\%. Of interest, multiple transfusions were also associated with a $35 \%$ incidence of ARDS when they occurred in medicine service patients without trauma. Long bone fractures were associated with the lowest incidence of ARDS of these three (11\%), whereas the incidence associated with lung contusion was intermediate $(22 \%)$. Patients with trauma including any or a combination of these three definitions had an overall ARDS incidence of $25.5 \%$.

On ALIVE study, it was found that mortality was independently associated with age and one variable reflecting underlying disease (immunoincompetence) with the severity of acute pulmonary and non-pulmonary organ failures (as reflected by the SAPS II and LOD scores) with acidosis $(\mathrm{pH}<7.30)$ and the occurrence of early barotrauma.

\section{Objectives}

1. To analyse the ARDS cases admitted patients with special reference to risk factors associated with poor prognosis.

2. To study the aetiology of ARDS.
3. To study severity and outcome of ARDS cases.

\section{MATERIALS AND METHODS}

This study was an observational study. 80 patients were included in the ARDS cohort, when meeting for the first time the consensus criteria for ARDS and not having any of the exclusion factors. Patients were classified as having ARDS when the worst $\mathrm{PaO} 2 / \mathrm{FiO} 2$ ratio recorded within the first 24 hours of inclusion was 300 or less.

\section{Diagnostic Criteria(3)}

Acute onset of respiratory distress with a relevant clinical setting-

a. Partial pressure of oxygen in arterial blood $\left(\mathrm{PaO}_{2}\right.$ $\mathrm{mmHg}) /$ fractional inspired oxygen $\left(\mathrm{FiO}_{2}\right)$ ratio $<300$.

b. Bilateral infiltrates on chest $\mathrm{x}$-ray.

c. An initial pulmonary artery occlusion pressure less than $18 \mathrm{mmHg}$ or no clinical evidence of left atrial hypertension or congestive cardiac failure at the time of presentation.

\section{Exclusion Criteria}

a. Age $<13$ years.

b. History of ischaemic heart disease or valvular heart disease or cardiomyopathies including diastolic dysfunction.

c. Patients having signs/ symptoms of cardiac failure like raised jugular venous pressure, raised central venous pressure and radiological features of high pressure oedema (cardiomegaly, dilated upper lobe vessels, Kerley's lines, central lung shadowing with absence of air bronchogram), ECG suggestive of ischaemic heart disease or accelerated hypertension or hypertensive heart disease as documented by 2D echo.

d. Chronic respiratory failure or patients with moderate-tosevere restrictive or Obstructive Lung Function. (COPD, ILD, lung resection, pulmonary tuberculosis active or old with fibrosis and destruction of lung parenchyma).

e. Death within 4 hours of admission.

A data collection of 80 patients is done in prospective and randomised manner and from a critical care unit in a tertiary care centre/ hospital. A minimum data set including demographic (age and gender) admission characteristics and discharge information (outcome, cause of death) was collected of all patients. This included demographic characteristics, the patient source (hospital, ward emergency or operating room or transfer), variables used for calculation of acute physiology and chronic health score (APACHE III), underlying diseases including immunoincompetence and its causes and the presence of chronic organ failure and comorbid conditions like diabetes mellitus, alcoholic liver disease etc. This comprised documentation of the diagnostic criteria for the syndrome, the primary cause(s) of ARDS and whether the initial insult was pulmonary ("Direct") or nonpulmonary ("Indirect").

Statistical analysis was done using patient related variables as well as process of care variables. Patient related variables included age, gender, diagnosis at the time of hospital admission, immunosuppression associated comorbid conditions and $\mathrm{pO}_{2} / \mathrm{FiO}_{2}$ ratio, while process of care variable included ventilatory support and settings, CCU stay, 
development of organ failure and outcome from CCU. For statistical analysis, patient having more than one diagnosis were put in one category. Patients developing sepsis irrespective of primary diagnosis like pneumonia were labelled as sepsis.

The data was studied and statistically treated. The univariate analysis was done using chi-square/ Fisher test and simple percentage. The test of significance was set $<0.05$. $\mathrm{T}$ test was done to test two groups where required.

\section{RESULTS}

For the present study, 80 patients were observed in medical CCU of tertiary care hospital and their outcomes for different categories under the requirement of study are as follows:

Out of 80 patients included in study 29 died, while 51 recovered completely.

\begin{tabular}{|c|c|c|c|c|c|c|c|}
\hline \multirow{3}{*}{ Age Group } & \multicolumn{4}{|c|}{ Outcome } & \multirow{3}{*}{ Total } & \multirow{3}{*}{$\begin{array}{c}\text { Chi- } \\
\text { Square }\end{array}$} & \multirow{3}{*}{ P value } \\
\hline & \multicolumn{2}{|c|}{ Recovered } & \multicolumn{2}{|c|}{ Death } & & & \\
\hline & $\mathbf{N}$ & (\%) & $\mathbf{N}$ & $(\%)$ & & & \\
\hline$<20$ years & 1 & 20 & 4 & 80 & 05 & \multirow{4}{*}{8.76} & \multirow{4}{*}{0.03} \\
\hline $20-40$ years & 29 & 78.38 & 8 & 21.62 & 37 & & \\
\hline $41-60$ years & 17 & 54.84 & 14 & 45.16 & 31 & & \\
\hline$>60$ years & 4 & 57.14 & 3 & 42.86 & 07 & & \\
\hline
\end{tabular}

The maximum number of patients died from the age group of 40 to 60 years that were $14(45.16 \%)$ and minimum number of patients died from age group $>60$ years that were $3(42.86 \%)$, while maximum percentage of patients died from the age group $<20$ years that is $80 \%$.

\begin{tabular}{|c|c|c|c|c|c|c|c|}
\hline \multirow{3}{*}{ Sex } & \multicolumn{4}{|c|}{ Outcome } & \multirow{3}{*}{ Total } & \multirow{3}{*}{$\begin{array}{l}\text { Chi- } \\
\text { Square }\end{array}$} & \multirow{3}{*}{$\begin{array}{c}P \\
\text { value }\end{array}$} \\
\hline & \multicolumn{2}{|c|}{ Recovered } & \multicolumn{2}{|c|}{ Death } & & & \\
\hline & $\mathbf{N}$ & $(\%)$ & $\mathbf{N}$ & $(\%)$ & & & \\
\hline Female & 22 & 57.90 & 16 & 42.10 & 38 & \multirow{2}{*}{1.07} & \multirow{2}{*}{0.30} \\
\hline Male & \begin{tabular}{|l|}
29 \\
\end{tabular} & 69.00 & 13 & 31.00 & 42 & & \\
\hline \multicolumn{8}{|c|}{ Table 2. Sex distribution of Patients } \\
\hline
\end{tabular}

\section{ARDS Severity Distribution}

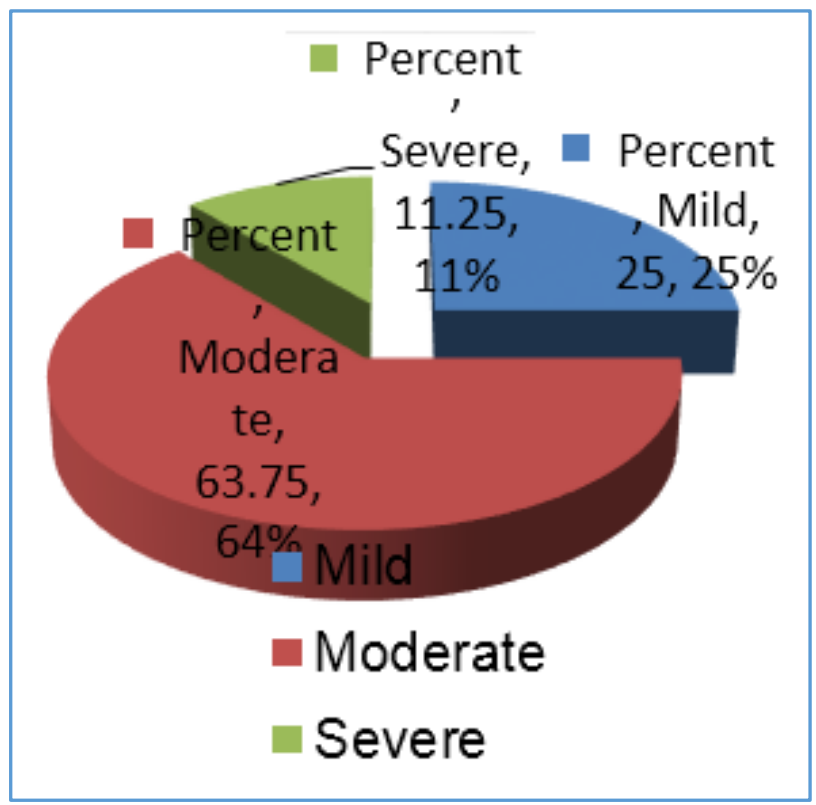

Figure 1. ARDS Severity Distribution
Out of 80 cases 20 were mild, 51 were moderate and 9 cases were severe ARDS.

\begin{tabular}{|c|c|c|c|c|c|}
\hline $\begin{array}{c}\mathrm{PO}_{2} / \\
\mathrm{FiO}_{2} \\
\text { Severity }\end{array}$ & Recovered & Death & Total & \begin{tabular}{|c} 
Chi- \\
Square \\
Test
\end{tabular} & $\begin{array}{c}P \\
\text { value }\end{array}$ \\
\hline Mild & $16(80.00 \%)$ & $4(20.00 \%)$ & 20 & \multirow{4}{*}{5.92} & \multirow{4}{*}{0.05} \\
\hline Moderate & $32(62.75 \%)$ & $19(37.25 \%)$ & 51 & & \\
\hline Severe & $3(33.33 \%)$ & $6(66.67 \%)$ & 9 & & \\
\hline Total & $51(63.75 \%)$ & $29(36.25 \%)$ & 80 & & \\
\hline \multicolumn{6}{|c|}{ Table 3} \\
\hline
\end{tabular}

From the table it is clear that out of 80 patients, maximum mortality were found in severe ARDS 66.67\%, while minimum found in mild ARDS $20 \%$.

\begin{tabular}{|c|c|c|c|c|c|c|}
\hline \multirow{3}{*}{$\begin{array}{l}\text { Sl. } \\
\text { No. }\end{array}$} & \multirow{3}{*}{$\begin{array}{c}\text { Suspected } \\
\text { Aetiology }\end{array}$} & \multicolumn{4}{|c|}{ Outcome } & \multirow{3}{*}{ Total } \\
\hline & & \multicolumn{2}{|c|}{ Recovered } & \multicolumn{2}{|c|}{ Death } & \\
\hline & & $\mathbf{N}$ & $(\%)$ & $\mathbf{N}$ & (\%) & \\
\hline 1 & Aspiration & 0 & 0.00 & 5 & 100.00 & 5 \\
\hline 2 & Burn & 0 & 0.00 & 1 & 100.00 & 1 \\
\hline 3 & Dengue & 18 & 94.70 & 1 & 5.30 & 19 \\
\hline 4 & Leptospirosis & 0 & 0.00 & 3 & 100.00 & 3 \\
\hline 5 & Malaria & 4 & 66.70 & 2 & 33.30 & 6 \\
\hline 6 & Malaria + Dengue & 2 & 100.00 & 0 & 0.00 & 2 \\
\hline 7 & Pancreatitis & 1 & 100.00 & 0 & 0.00 & 1 \\
\hline 8 & Poisoning & 0 & 0.00 & 2 & 100.00 & 2 \\
\hline 9 & Pulmonary Infection & 25 & 83.30 & 5 & 16.70 & 30 \\
\hline 10 & Sepsis & 1 & 10.00 & 9 & 90.00 & 10 \\
\hline 11 & Transfusion Reaction & 0 & 0.00 & 1 & 100.00 & 1 \\
\hline \multicolumn{7}{|c|}{ Table 4. Aetiology Distribution } \\
\hline
\end{tabular}

Pulmonary infection was the most common cause of ARDS in our study with highest number of cases (30) with $16.70 \%$ of mortality followed by Dengue (19 cases) with mortality of 5.30\%. ARDS secondary to Sepsis associated with $90.00 \%$ mortality. Malaria (6 cases) as a cause of ARDS was found with $33.30 \%$ mortality. However, the less common causes of ARDS like Aspiration, Burn, Leptospira, Poisoning and Transfusion Reaction was associated with 100\% mortality. The highest cases of recovery was found in dengue ARDS.

It was found that the clinical outcome in terms of mortality significantly different among different aetiologies with p-value $<0.0001$.

\begin{tabular}{|c|c|c|c|c|c|}
\hline \multirow{3}{*}{$\begin{array}{c}\text { Tracheal/ } \\
\text { Sputum } \\
\text { Culture }\end{array}$} & \multicolumn{4}{|c|}{ Outcome } & \multirow{3}{*}{ Total } \\
\hline & \multicolumn{2}{|c|}{ Recovered } & \multicolumn{2}{|c|}{ Death } & \\
\hline & $\mathbf{N}$ & (\%) & $\mathbf{N}$ & (\%) & \\
\hline Acinetobacter & 1 & $7.10 \%$ & 13 & $92.90 \%$ & 14 \\
\hline H. influenza & 0 & $0.00 \%$ & 7 & $100.00 \%$ & 07 \\
\hline Klebsiella & 10 & $83.30 \%$ & 2 & $16.70 \%$ & 12 \\
\hline MRSA & 4 & $66.70 \%$ & 2 & $33.30 \%$ & 6 \\
\hline Pneumococci & 7 & $87.50 \%$ & 1 & $12.50 \%$ & 08 \\
\hline No Growth & 29 & $87.90 \%$ & 4 & $12.10 \%$ & 33 \\
\hline
\end{tabular}

Table 5. Tracheal/Sputum Culture versus Outcome

Chi-Square $=44.003 ;$ P-value $<0.0001$

Tracheal or Sputum culture has been done in 80 patients and found to be positive in 47 (58.75\%). 25 (53.19\%) culture positive patient have died, while 22 patients (46.80\%) have 
been recovered. 14 patients $(29.78 \%)$ were found to be culture positive for Acinetobacter and only 1 patient has been recovered. Statistical analysis of culture positivity and outcome showed significant correlation with $p$-value $<0.0001$.

\begin{tabular}{|c|c|c|c|}
\hline X-Ray on Admission & Recovered & Death & Total \\
\hline Bilateral Infiltrate & 32 & 24 & $\mathbf{5 6}$ \\
\hline Normal & 19 & 5 & $\mathbf{2 4}$ \\
\hline
\end{tabular}

Table 6. X-ray on admission with Features of ARDS

\begin{tabular}{|c|c|c|c|c|c|c|c|c|c|c|c|c|}
\hline \multirow{3}{*}{ Variables } & \multicolumn{10}{|c|}{ "Outcome } & \multirow{3}{*}{ T-test } & \multirow{3}{*}{ P-value } \\
\hline & \multicolumn{5}{|c|}{ Recovered } & \multicolumn{5}{|c|}{ Death } & & \\
\hline & Mean & SD & Median & Min & Max & Mean & SD & Median & Min & Max & & \\
\hline Age & 40 & 14 & 38 & 19 & 72 & 41 & 17 & 46 & 15 & 72 & 0.21 & 0.84 \\
\hline Resp. Rate & 25 & 6 & 24 & 14 & 36 & 27 & 8 & 28 & 14 & 38 & 1.42 & 0.16 \\
\hline SBP & 118 & 15 & 118 & 90 & 148 & 102 & 19 & 98 & 76 & 142 & 4.08 & 0.0001 \\
\hline DBP & 68 & 9 & 70 & 50 & 86 & 62 & 9 & 60 & 50 & 80 & 3.21 & 0.002 \\
\hline HR & 100 & 15 & 100 & 70 & 130 & 111 & 20 & 112 & 78 & 144 & 2.68 & 0.009 \\
\hline Temp & 99.91 & 2.11 & 99.4 & 96.2 & 104.6 & 101.1 & 4.63 & 100.4 & 96 & 122 & 1.56 & 0.12 \\
\hline $\mathrm{Hb}$ & 11.55 & 1.41 & 11.5 & 7.7 & 14.4 & 10.62 & 2.14 & 10.6 & 6.6 & 16.4 & 2.34 & 0.02 \\
\hline WBC & 8986 & 3281 & 8000 & 3000 & 16500 & 12234 & 5461 & 13500 & 3200 & 26000 & 3.33 & 0.0013 \\
\hline ESR & 30 & 19 & 24 & 10 & 110 & 40 & 23 & 38 & 10 & 110 & 2.05 & 0.04 \\
\hline Platelets & 201824 & 120681 & 164000 & 32000 & 450000 & 264655 & 385557 & 142000 & 26000 & 1700000 & 1.08 & 0.28 \\
\hline Creatinine & 0.91 & 0.44 & 0.9 & 0.2 & 2.4 & 2.06 & 1.46 & 1.7 & 0.2 & 6.1 & 5.25 & $<0.0001$ \\
\hline Urea & 24 & 12 & 21 & 12 & 88 & 44 & 23 & 36 & 14 & 90 & 5.01 & $<0.0001$ \\
\hline $\mathrm{Na}^{+}$ & 134 & 16 & 136 & 33 & 151 & 127 & 20 & 129 & 32 & 144 & 1.78 & 0.08 \\
\hline $\mathrm{K}^{+}$ & 4.22 & 0.74 & 4.2 & 2.2 & 5.5 & 4.22 & 1.19 & 4.2 & 2.5 & 6.5 & 0.01 & 0.99 \\
\hline SGOT & 86 & 91 & 64 & 18 & 540 & 85 & 103 & 60 & 16 & 540 & 0.05 & 0.96 \\
\hline SGPT & 121 & 121 & 85 & 16 & 740 & 154 & 154 & 80 & 24 & 540 & 1.05 & 0.29 \\
\hline $\mathrm{PO} 2 / \mathrm{FiO} 2$ & 171 & 27 & 180 & 80 & 196 & 159 & 41 & 174 & 80 & 196 & 1.57 & 0.12 \\
\hline Albumin & 4.22 & 0.74 & 4.2 & 2.2 & 5.5 & 4.22 & 1.19 & 4.2 & 2.5 & 6.5 & 0.01 & 0.99 \\
\hline Urine Input & 2400 & 599 & 2400 & 1200 & 3600 & 1959 & 570 & 2000 & 1000 & 3200 & 3.22 & 0.002 \\
\hline Urine Output & 1831 & 600 & 1900 & 600 & 3200 & 1164 & 706 & 1000 & 100 & 2800 & 4.48 & $<0.0001$ \\
\hline GCS & 15 & 0 & 15 & 15 & 15 & 13 & 3 & 15 & 6 & 15 & 4.42 & $<0.0001$ \\
\hline $\begin{array}{c}\text { Ventilator } \\
\text { Invasive } \\
\text { Mode (Days) }\end{array}$ & 3 & 2 & 3 & 0 & 8 & 6 & 2 & 6 & 3 & 11 & 6.83 & $<0.0001$ \\
\hline $\begin{array}{c}\text { Ventilator } \\
\text { Non-Invasive } \\
\text { Mode (Days) }\end{array}$ & 3 & 1 & 3 & 1 & 5 & 1 & 1 & 1 & 0 & 3 & 7.05 & $<0.0001$ \\
\hline $\begin{array}{c}\text { Ventilator } \\
\text { Total (Days) }\end{array}$ & 6 & 2 & 6 & 2 & 10 & 7 & 2 & 6 & 4 & 13 & 3.34 & 0.0013 \\
\hline ICU Stay (Days) & 9 & 2 & 8 & 5 & 14 & 8 & 2 & 8 & 4 & 13 & 1.71 & 0.09 \\
\hline & & & V & $P a$ & eter & the & cio & vith & & & & \\
\hline
\end{tabular}

\section{DISCUSSION}

All the patients included in our study had acute respiratory distress syndrome with $\mathrm{pO}_{2} / \mathrm{FiO}_{2}$ ratio $<300$. Severity of ARDS and its association and correlation with various factors pertaining to patient himself, the illness causing admission to medical intensive care unit and outcome in the form of survival were studied.

Our study was carried in exclusive medical intensive care unit and all surgical patients including trauma patients were not considered.

In critically ill patients hospitalised in critical care units (CCU), the prevalence of ARDS has been estimated at about 5$15 \%$ of patients. ${ }^{11,9,12,13}$ In our study period, there were 800 admissions with prevalence of ARDS $12.50 \%$. In our study, overall mortality was $36.25 \%$.

In the recent International survey of mechanically ventilated patients, the ICU mortality rate of the 231 patients with ARDS on ICU admission was 52\%. ${ }^{9}$ In other single-centre epidemiological studies of unselected patients, mortality
Cases with x-ray suggestive of bilateral infiltrate on admission were 56 , while the first $\mathrm{x}$-ray study was normal among 24 cases. 
shown in several studies. However, in a study conducted in North India by Agarwal et $\mathrm{al}^{22}$ it was observed that when patient aged more than 50 years were compared to younger patients, the outcome was not significantly different.

In our study, out of 80 patients $42(52.5 \%)$ were male patients and $38(47.5 \%)$ were female patients. As per previous studies, gender appears to have no effect on the likelihood of developing ARDS given similar risk conditions. ${ }^{16,23}$ Our results were consistent with these studies.

The specific infections related to severe sepsis vary considerably by geographic area. For example, leptospirosis is a common cause of ARDS in Brazil ${ }^{23}$ and also in Thailand, India and other tropical countries, but not in the United States or Western Europe.

Pulmonary infection (37.5\%) followed by Dengue $(23.75 \%)$ were the most common causes for ARDS in this study. A study conducted by Vigg et al in Hyderabad had made similar observations with primary pulmonary infection being the most common cause of ARDS. In $43.75 \%$ of the patients in the study ARDS could be attributed to direct causes, predominantly pulmonary infection. Ninety five percent of the cases of ARDS in this study were secondary to infectious causes. Our results were consistent with this study.

In our study, sepsis was the predominant indirect cause of ARDS with 35 out of 80 patients of Dengue, i.e. 19 (23.75\%). Sepsis was the next leading causes of ARDS contributing $12.5 \%$. Other major causes of ARDS were Malaria and Leptospirosis contributing $10.25 \%$.

Direct causes of acute respiratory distress syndrome were pneumonia and aspiration together contributing to $43.75 \%$ of patients. Among indirect non-pulmonary nontropical causes sepsis was the most common, causing acute ARDS in $10(12.5 \%)$ patients.

Other causes which contributed to acute respiratory distress syndrome was poisoning (2), Burn (1) and Transfusion Reaction (1).

A number of factors related to underlying conditions, aetiologies, severity of lung injury, non-pulmonary organ failure and management have been identified in outcome studies of ARDS.9,12,13,21,24,25,26 The principal variables influencing outcome appear to be chronic liver disease 12,20 and immunodepression, 12,13,21 sepsis $(\mathrm{OR}=2.8)^{13,20}$ and the occurrence of non-pulmonary organ dysfunction.13,21,25

In our study, significant association was seen between mortality and aetiology of ARDS. Mortality was $27.30 \%$ in patients with alcoholic liver disease. One study has found that chronic alcoholism carries an increased risk of development of ARDS, given similar risk conditions as observed by Moss M, Bucher B, Moore FA et al (1996).

Patients with ARDS had lower $\mathrm{PO}_{2}$, lower $\mathrm{pO}_{2} / \mathrm{FiO}_{2}$ ratio, severe metabolic acidosis, higher serum creatinine, higher blood urea nitrogen and worsened critical scores including GCS scoring, lower systolic blood pressure and lower mean arterial pressure.

A low $\mathrm{pH}$ was associated with increased mortality points to the adverse impact of metabolic acidosis on outcome. This finding probably reflects circulatory failure and underlying severity.

This observation supports the previous literature and postulations that ARDS is part of a systemic syndrome, now called multiple organ failure, in which the lung features heavily but may also include renal failure and injury to liver, gut and skin. ${ }^{26}$

In patients with ARDS, most of the deaths occurred in six to ten days suggesting rapid course of underlying pathology. The fact that most cases of ARDS occur quickly after the onset of the clinical predisposition underscores the potential need for rapid intervention in these patients.

A study conducted by Michelle Ng Gong had noted that the number of units of blood products transfused were significantly higher in the group of patients that died compared to those that recovered. This apparent increase in mortality amongst patients transfused larger volumes of blood products, may be either because this group has a greater degree of organ dysfunction thus necessitating transfusions or may indicate that the transfusions have contributed to the lung injury. Our study showed that there was significant association between number of blood products transfused and mortality ( $\mathrm{p}$-value 0.004 ).

In this study, there was microbiological growth in trachea or sputum cultures were taken in $100 \%$ patients. Where $58.75 \%$ patients were having microbial growth, out of which $53.19 \%$ patients died. This culture positivity was significantly associated with mortality (p-value 0.0001).

Patients with ARDS were put on ventilator with guidelines from recent ARDS network trial with all patients initially put on assist control volume control pressure support mode with initial tidal volume $6 \mathrm{mg}$ per $\mathrm{kg}$ body weight. PEEP was increased whenever possible to increase $\mathrm{PaO}_{2}$ and decrease requirement of $\mathrm{FiO}_{2}$, so as to keep $\mathrm{FiO}_{2}$ at or below 60 and to keep end inspiratory plateau pressure $<30 \mathrm{~cm} \mathrm{H} 20$. All patients included in this study required ventilator support.

\section{Limitations}

- The relatively small number of ARDS cases that we were able to document.

- It is possible that we missed some patients with our defined clinical risk conditions.

- $\quad$ Left atrial pressure was not directly measured causing exclusion of large number of patients.

- Long-term morbidity and mortality were not studied.

- Study was only observational and non-interventional.

- Because of the overwhelming nature of the lung injury, once it is established, prevention would appear to be the most effective strategy for improving the outlook in this condition.

\section{CONCLUSION}

1. Prevalence of acute respiratory distress syndrome is quite common in ICU setting.

2. Pulmonary infection was the most common nontropical direct cause of ARDS, while sepsis was the most common cause of indirect ARDS.

3. Dengue, Malaria and Leptospirosis were most common tropical causes of ARDS.

4. Factors that showed association with mortality-

- Aetiology had significant association with outcome.

- Anaemia, tachycardia, raised ESR and high WBC count had significant association with outcome. 
- Deranged serum creatinine and decreased urine output had significant association with outcome.

- Low systolic blood pressure and low diastolic blood pressure were significantly associated with poor outcome.

- Duration of ventilator support was associated with mortality significantly.

- Culture positivity was associated significantly with mortality.

\section{REFERENCES}

[1] Ashbaugh DG, Bigelow DB, Petty TL, et al. Acute respiratory distress in adults. Lancet 1967;2(7511):319-23.

[2] Murray JF, Matthay MA, Luce JM, et al. An expanded definition of the adult respiratory distress syndrome. Am Rev Respir Dis 1988;138(3):720-3.

[3] Bernard GR, Artigas A, Brigham KL, et al. The American-European Consensus Conference on ARDS. Definitions, mechanisms, relevant outcomes and clinical trial coordination. Am J Respir Crit Care Med 1994;149(3 Pt 1):818-24.

[4] Luce JM. Acute lung injury and the acute respiratory distress syndrome. Crit Care Med 1998;26(2):369-76.

[5] Garber BG, Hebert PC, Yelle JD, et al. Adult respiratory distress syndrome: a systemic overview of incidence and risk factors. Crit Care Med 1996;24(4):687-95.

[6] Zielberberg MD, Epstein SK. Acute lung injury in the medical ICU: comorbid conditions, age, aetiology and hospital outcome. Am J Respir Crit Care Med 1998;157(4 Pt 1):1159-64.

[7] Hudson LD, Steinberg KP. Epidemiology of acute lung injury and ARDS. Chest 1999;116(Suppl 1):74S-82S.

[8] Atabai A, Matthay MA. The pulmonary physician in critical care. 5: acute lung injury and the acute respiratory distress syndrome: definitions and epidemiology. Thorax 2002;57(5):452-8.

[9] Milberg JA, Davis DR, Steinberg KP, et al. Improved survival of patients with acute respiratory distress syndrome (ARDS): 1983-1993. JAMA 1995;273(4):306-9.

[10] Monchi M, Bellenfant F, Cariou A, et al. Early predictive factors of survival in the acute respiratory distress syndrome. A multivariate analysis. Am J Respir Crit Care Med 1998;158(4):1076-81.

[11] Esteban A, Anzueto A, Frutos F, et al. Characteristics and outcomes in adult patients receiving mechanical ventilation: a 28-day international study. JAMA 2002;287(3):345-55.

[12] Roupie E, Lepage E, Wysocki M, et al. Prevalence, etiologies and outcome of the acute respiratory distress syndrome among hypoxemic ventilated patients. SRLF Collaborative Group on Mechanical Ventilation. Societe de Reanimation de Langue Francaise. Intensive Care Med 1999;25(9):920-9.
[13] Amato MBP, Barbas CSV, Medeiros DM, et al. Effect of a protective-ventilation strategy on mortality in the acute respiratory distress syndrome. N Engl J Med 1998;338(6):347-54.

[14] Ware LB, Matthay MA. The acute respiratory distress syndrome. N Engl J Med 2000;342(18):1334-49.

[15] Fraser RS, Muller NL, Colman N, et al. Acute respiratory distress syndrome. In: Fraser RS, Pare PD, eds. Fraser and Fare's diagnosis of diseases of the chest. $4^{\text {th }}$ edn. Philadelphia: WB Saunders 1999;3:97699.

[16] Hudson LD, Milberg JA, Anardi D, et al. Clinical risks for development of the acute respiratory distress syndrome. Am J Respir Crit Care Med 1995;151(2 Pt 1):293-301.

[17] Fowler AA, Hamman RF, Good JT, et al. Adult respiratory distress syndrome: risk with common predispositions. Ann Intern Med 1983;98(5 Pt 1):5937.

[18] Luhr OR, Antonsen K, Karlsson M, et al. Incidence and mortality after acute respiratory failure and acute respiratory distress syndrome in Sweden, Denmark and Iceland. The ARF Study Group. Am J Respir Crit Care Med 1999;159(6):1849-61.

[19] Estenssoro E, Dubin A, Laffaire E, et al. Incidence, clinical course and outcome in 217 patients with acute respiratory distress syndrome. Crit Care Med 2002;30(11):2450-6.

[20] Eisner MD, Thompson T, Hudson LD, et al. Efficacy of low tidal volume ventilation in patients with different clinical risk factors for acute lung Injury and the acute respiratory distress syndrome. Am J Respir Crit Care Med 2001;164(2):231-6.

[21] Suchyta MR, Clemmer TP, Elliot CG, et al. The adult respiratory distress syndrome. A report of survival and modifying factors. Chest 1992;101(4):1074-9.

[22] Gong MN, Thompson BT, Williams P, et al. Clinical predictors of and mortality in acute respiratory distress syndrome: potential role of red cell transfusion. Crit Care Med 2005;33(6):1191-8.

[23] Artigas A, Carlet J, LeGall JR, et al. Clinical presentation, prognostic factors and outcome of ARDS in the European Collaborative Study (1985-1987): a preliminary report. In: Zapol WM, Lemaire F, eds. Adult respiratory distress syndrome (in the series 'Lung Biology in Health and Disease', vol. 50. edited by Lenfant C). New York, NY: Marcel Dekker Publishing Company, 1991: p. 37-64.

[24] Doyle RL, Szaflarski N, Modin GW, et al. Identification of patients with acute lung injury. Predictors of mortality. Am J Respir Crit Care Med 1995;152(6 Pt 1):1818-24.

[25] Vigg A, Mantri S, Vigg A, et al. Clinical profile of ARDS. JAPI 2003;51:855-8.

[26] Agarwal R, Aggarwal AN, Gupta D, et al. Aetiology and outcomes of pulmonary and extrapulmonary acute lung injury/ARDS in a respiratory ICU in North India. Chest 2006;130(3):724-9. 